\title{
Consumo midiático da beleza feminina e o sonho de ser modelo profissional
}

\section{Daniela Schmitz}

\section{Resumo}

Este texto objetiva discutir como o consumo midiático do universo das modelos profissionais pode estar relacionado com o desejo de garotas em seguir essa profissão. 0 referencial teórico parte da perspectiva sociocultural do consumo de García Canclini e das ideias de Campbell acerca das relações entre o consumo e o hedonismo moderno. Apresenta alguns dados construídos a partir de entrevistas e questionários aplicados a um grupo de 120 garotas. Como principais resultados, destaca-se que, para a maioria, a mídia age como propulsora do sonho desde a fase infantil e opera mais na transmissão dos ideais de fama, glamour e projeção social do que no regramento da aparência destas jovens.

\section{Palavras-Chave}

Consumo midiático. Modelo. Sonho.
Daniela Schmitz I danischmitz@ymail.com Pós-doutoranda por meio do Programa de Pós-Graduação em Comunicação e Informação da Universidade Federal do Rio Grande do Sul, bolsista PNPD-CAPES; concluiu o Doutorado na mesma instituição. É formada em Publicidade e Propaganda pela Universidade do Vale do Rio dos Sinos, onde também obteve 0 título de mestre em Ciências da Comunicação.

\section{Profissão modelo}

Historicamente, a mulher tem sua posição social bastante atrelada ao corpo, seja pelas funções reprodutivas que lhe cabem, seja pelas frequentes associações (e exigências) entre o feminino e a beleza, como discutem Lipovetsky (2000), Del Priore (2000) e Wolf (1992). Também não é novidade que uma parte das garotas já desejou alguma posição ou profissão relacionada unicamente à aparência física. Os concursos de Miss, ainda que tenham perdido popularidade, já fizeram muito sucesso no Brasil. Estes seguem uma lógica com acesso bastante restrito, uma vez que, anualmente, apenas uma garota é eleita ao posto máximo. Mas a partir dos anos 1980, e mais fortemente nos 1990, a profissão de modelo ${ }^{1}$ começa a ganhar destaque, 0 que amplia 0 acesso a esse posto de "referência de beleza", em comparação à dinâmica que rege os concursos de Miss.

A notoriedade que a profissão atingiu neste período está ligada também ao posto de celebridades midiáticas que algumas modelos alcançaram. Em meados de 1990, um pequeno 
grupo de top models recebia por ano milhões de dólares para expor sua imagem e associála aos mais diversos produtos, na chamada profissionalização da beleza feminina (Lipovetsky, 2000). São mulheres a serem copiadas pela aparência, e sua popularidade provém justamente dela, tomada como um ideal, mesmo distante do padrão corporal da grande maioria.

No começo dos anos 2000, o Brasil adentra 0 circuito internacional da beleza, tornando-se um grande exportador de beldades, como Gisele Bündchen, a top model mais bem paga no mundo. Ela tem espaço cativo na mídia e é responsável por boa parte da fama atribuída às profissionais brasileiras no exterior.

Sobre esta "profissão da beleza", interessa destacar o quanto a participação dessas figuras no campo midiático impulsiona o seu sucesso, assim como aumenta 0 desejo das jovens de fazer parte desse universo, que evoca beleza, viagens, projeção social, dinheiro e fama de forma rápida e em idade precoce.

Sendo assim, o propósito deste artigo é discutir as relações entre 0 consumo midiático da beleza feminina e 0 desejo de ser modelo profissional entre jovens garotas ${ }^{2}$. No entanto, antes de apresentar e discutir os dados empíricos construídos em vários procedimentos, traça-se um breve panorama do referencial teórico que guiou a investigação, bem como a metodologia utilizada.

\section{Da perspectiva sociocultural do consumo ao consumo midiático}

0 aporte teórico da investigação centrou-se nas noções de consumo cultural, tomando o consumo midiático como uma operação específica dentro deste. Como preâmbulo a essa discussão, partese da ideia que, após romper com alguns dos principais preconceitos que cercavam (e, por vezes, ainda cercam) o consumo, tem-se hoje um cenário reconhecido como sociedade de consumo (Bauman, 2008; Baudrillard, 1995).

Há autores como Appadurai (2001) e Campbell (2001) que apontam para uma associação entre prazer e consumo na atualidade, porém divergem em relação ao processo imaginativo mobilizado pelo consumo simbólico. Para o primeiro, 0 trabalho da imaginação se vale de experiências de um passado recente, enquanto o segundo defende que 0 poder imaginativo e fantasioso prescinde dessa experimentação prévia, constituindo-se de um prazer autoilusivo, típico do hedonismo moderno. Para Campbell (2001), a base do consumo moderno está centrada na construção imaginativa acerca dos bens e não propriamente

Profissionais que trabalham na divulgação, seja em desfiles, editoriais ou peças publicitárias de artigos de moda, mas também de produtos e serviços diversos.

2 Esta problemática faz parte de uma tese (SCHMITZ, 2013) que investigou as mediações da mídia e da família na construção do desejo de ser modelo, sendo que este artigo discute apenas o primeiro eixo. 
na compra e uso dos mesmos, e este entendimento abarca também as ofertas da mídia. Considerando especificamente os produtos midiáticos que envolvem as modelos profissionais - mais intensamente na área da moda, mas também na publicidade em geral -, tem-se uma amplitude de mensagens que o retratam como um universo de luxo, como pontuou Pereira (2008). Ou seja, entende-se que 0 enquadramento midiático da profissão instiga e facilita 0 sonho, 0 devaneio e a imaginação, processos que caracterizam o hedonismo moderno, mais imaginativo que sensorial, aos olhos de Campbell (2001).

Dito isso, compreende-se que, mesmo que os autores anteriormente referidos ajudaram a compreender a realidade social que circunscreve o objeto pesquisado, é importante demarcar que a principal perspectiva teórica que guiou a discussão sobre 0 consumo foi a sociocultural, de García Canclini (2006). Em seus apontamentos, ainda que não tenha chegado ao status de um modelo teóricometodológico para enfrentamento do tema, 0 autor reivindica um olhar mais amplo, plural e interdisciplinar sobre 0 ato de consumir: "reconceitualizar o consumo, não como cenários de gastos inúteis e impulsos irracionais, mas como espaço que serve para pensar, e no qual se organiza grande parte da racionalidade econômica, sociopolítica e psicológica nas sociedades" (2005, p.14).
Na construção de sua argumentação, destaca 0 consumo como sendo "um conjunto de processos socioculturais em que se realizam a apropriação e os usos dos produtos" (2006, p. 80) (traduz-se) ${ }^{3}$. Também apresenta seis perspectivas a partir das quais as disciplinas 0 abordam parcialmente, muito embora no processo de aquisição, uso e apropriação de produtos estas se articulem. Elas são resumidas da seguinte forma: a) Lugar de reprodução da força de trabalho e expansão do capital: parte da lógica econômica, com base marxista. Possui visão unidimensional, pois foca nas estratégias do mercado, no ciclo de produção e reprodução social. b) Cenário de disputas pela apropriação do produto social: parte da lógica sociopolítica interativa. Traz uma visão mais relacional, pois foca o espaço de interação entre oferta e demanda; é aqui que as estratégias diferenciadas de aquisição e utilização dos bens ganham espaço. c) Lugar de diferenciação social e distinção simbólica entre classes: parte da lógica consumidora, com base nos estudos de Bourdieu. Tem foco na dinâmica de distinção social buscada a partir do consumo, na qual a diferenciação é o motor da economia dos bens simbólicos. d) Sistema de integração e comunicação: de lógica integrativa, foca no consumo como integrador de classe. É um contraponto à lógica anterior, todavia não desconsidera os elementos de distinção inscritos no ato de consumir, porém, pressupõe-se que, para que a distinção se opere, é preciso haver um compartilhamento de sentidos a respeito. e) 
Processo ritual: parte da lógica ritualística, pois foca nos aspectos de rito inscritos no consumo, explorando sua organização/operação. f) Cenário de objetivação de desejos: parte de uma lógica irracional, foca no consumo como fruto do desejo, que está para além das necessidades, e que não pode ser satisfeito pelas instituições. De difícil apreensão empírica, mas serve para pontuar que o consumo também opera em outra gramática não acionada pelo consciente.

Na investigação, partiu-se das reivindicações de García Canclini (2006): compreender o consumo sem um recorte imposto por uma vinculação disciplinária única, adotando um olhar plural sobre 0 fenômeno. Um olhar que se constrói transversalmente ao que essas teorias propõem, mas não necessariamente abarque todas elas, pois se trata de um consumo cultural muito específico, focado nos modelos de beleza midiatizada. Deste modo, não se teve por objetivo destrinchar 0 objeto concreto para "encaixá-lo" nas seis teorias, pois se buscou analisar o consumo midiático das jovens de maneira exploratória sem um raciocínio estruturador preconcebido $0^{4}$. Ou seja, o princípio articulador dessas perspectivas emergiu do empírico, das reivindicações de entendimento do objeto concreto, observando as lógicas do consumo, dos usos e dos sentidos que as garotas atribuem aos conteúdos midiáticos.
Assim posto, para entender a participação da mídia como instância de mediação (MartínBarbero, 2003) na construção do desejo de ser modelo, o lugar analítico encontrou-se no "entre" e no "através" das seis abordagens que García Canclini indica como perspectivas a partir das quais o consumo já foi explicado. Para que essa proposta analítica se operasse, as estratégias metodológicas foram construídas para possibilitar a emersão de vários aspectos implicados no consumo de padrões midiáticos de beleza feminina, mais especificamente de modelos profissionais.

Importante demarcar que, para García Canclini (2006), todo o consumo é cultural, ainda que proponha uma distinção que coloca 0 "consumo cultural" como um processo à parte. Faz essa distinção com base nas particularidades do campo artístico e da produção intelectual e dos circuitos independentes em que transitam. Não se quer adentrar na discussão da pertinência desta distinção sobre tipos de consumo, mas concorda-se com 0 autor quando enuncia que determinados produtos têm sua importância inscrita mais nos valores simbólicos a ele atribuídos do que nos utilitários ou mercantis, "ou ao menos estes últimos se configuram subordinados à dimensão simbólica" (García Canclini, 2006, p. 89) (traduz-se) $)^{5}$.

Também não se pretendeu construir um modelo teórico-metodológico que abarque as seis teorias, reivindicação de longa data de García Canclini e sobre a qual o autor não fechou questão.

No original: "[...] o donde al menos estos últimos se configuran subordinados a la dimensión simbólica" (GARCIA CANCLINI, 2006, p. 89). 
Entende-se que o consumo midiático estaria incluído no que 0 autor chama de consumo cultural, o que já foi evidenciado por García Canclini (2006) quando expõe que, muito embora as exigências econômicas interfiram na produção, no estilo e na circulação dos produtos midiáticos, estes últimos possuem uma determinada autonomia que diz respeito à dinâmica própria de seus processos produtivos e seu consumo, o que torna possível tomá-los como bens culturais.

Mesmo que os estudos de recepção e consumo de mídia sejam correntes no país há mais de 20 anos (Jacks, 2008; 2014), pouco se discute sobre as especificidades do consumo midiático. Toaldo e Jacks (2013), em uma tentativa recente de discorrer a respeito, ponderam que se trata

do consumo do que a mídia oferece: nos grandes meios - televisão, rádio, jornal, revista, internet, sites, blogs, celulares, tablets, outdoors, painéis ... - e nos produtos/conteúdos oferecidos por esses meios - novelas, filmes, notícias, informações, entretenimentos, relacionamentos, moda, shows, espetáculos, publicidade, entre outros. Neste contexto, a oferta da mídia inclui também o próprio estímulo ao consumo, que se dá tanto através da oferta de bens (por meio do comércio eletrônico e da publicidade), quanto no que se refere a tendências, comportamentos, novidades, identidades, fantasias, desejos... (Toaldo; Jacks, 2013, pp 06-07)

Por fim, destaca-se que a noção de consumo midiático aqui se distingue de um estudo clássico de recepção, mais centrado na produção de sentidos acerca de um produto midiático específico. Tal filiação teórico-metodológica se deve ao fato da investigação estar mais centrada em uma análise diagonal sobre o consumo midiático da beleza feminina entre as jovens. Buscou-se muito mais elencar os meios, os produtos e as figuras femininas que faziam sucesso na mídia ao longo do relacionamento com os meios de comunicação e não focalizar um produto midiático em particular que tenha sido determinante na construção do desejo de ser modelo, o que estaria mais relacionado aos pressupostos que orientam um estudo de recepção.

Sendo assim, a perspectiva do consumo midiático apresentou-se relevante para a investigação a fim de aprofundar a análise dos múltiplos usos dos padrões midiáticos de beleza das jovens. Essa perspectiva permitiu compreender como se conformam os palimpsestos do consumo midiático, os quais, de alguma forma, dizem respeito aos fluxos de consumo dos meios. A noção de palimpsesto é apropriada de MartínBarbero (2003) e, originalmente, é associada ao âmbito da produção, mais especificamente ao emaranhado de gêneros que se constitui a TV. Em "Os exercícios do ver", Martín-Barbero e Rey (2001), ainda se referindo ao contexto da produção, contrapõem a noção ao conceito de hipertexto. Assim, palimpsesto é associado à memória inscrita em cada produto textual e à pluralidade de tempos, e pode ser tomado como "o texto no qual um passado apagado emerge tenazmente, embora imprecisamente, nas entrelinhas escritas pelo presente" (2001, p. 63). Entretanto, toma-se a noção para trabalhá- 
la desde a perspectiva do consumo, em que os palimpsestos são considerados como a trama de textos provenientes das fontes mais diversas (midiáticas ou não), que se cruzam no processo de consumo das garotas que desejam ser modelos.

\section{Procedimentos metodológicos}

Na construção da pesquisa, optou-se por trabalhar com garotas que estivessem em dois níveis em relação ao desejo de ser modelo: de um lado, aquelas que já tivessem participado de algum concurso ou entrado em contato com alguma agência de modelos ou até já estivessem agenciadas, mas em início de carreira; de outro, as que ainda mantinham a idealização da profissão em nível de "sonho", que não tivessem realizado nenhuma ação efetiva em busca dele. No total, 120 garotas, entre 9 e $30^{6}$ anos, participaram da pesquisa ${ }^{7}$, das quais $76 \%$ são gaúchas.

0 consumo midiático sobre 0 universo das modelos e a beleza feminina foi explorado a partir de dois procedimentos que foram construídos em vista dos objetivos da pesquisa: entrevistas individuais e em dupla (mãe e filha) ${ }^{8}$, questionários aplicados online e presencialmente. Na construção dos dados, cada técnica foi aplicada com grupos distintos de garotas.

Essa configuração foi pensada a partir de uma proposta proferida por Orozco Gómez em palestra no PPGCOM da UFRGS, em 16/09/09, quando sugeriu que as várias entradas em campo de uma mesma pesquisa poderiam ser realizadas com grupos distintos, desde que o perfil principal fosse mantido, o que efetivamente ocorreu. Como principal justificativa para este procedimento, destaca-se que 0 cerne da investigação dava conta do contexto do "sonho coletivo" de ser modelo.

A técnica do questionário foi criada especificamente para explorar o consumo midiático das jovens. E este consumo foi mapeado de três formas: a) em respostas espontâneas sobre 0 consumo de informações do universo das modelos, sem que a pergunta remetesse a espaços midiáticos; b) de forma induzida com foco no consumo de mídia em geral. Questionou-se sobre a frequência de consumo e as preferências sobre TV aberta e por assinatura, internet, rádio, revistas, jornais e cinema para ver se havia alguma predileção por produtos que remetessem ao universo das modelos; c) de forma induzida com foco no consumo de conteúdos midiáticos sobre modelos. Neste terceiro momento, questionouse 0 que já haviam consumido sobre modelos nos

0 limite etário que se havia estabelecido era de 25 anos, pois esta é a idade máxima permitida na maioria dos concursos e seleções de modelos. Porém, três mulheres acima desta idade responderam ao questionário online e optou-se por não desconsiderar suas participações. Esse intervalo de idade está de acordo com a discussão sobre a juventude empreendida na tese.

0 grupo pesquisado foi construído com indicações da rede de relacionamentos da pesquisadora e de abordagens diretas em seleções e concursos de modelos realizados em Porto Alegre.

Para alcançar todos os objetivos da pesquisa, incluiu-se ainda o procedimento de observação de inspiração etnográfica, contudo, este não foi utilizado para compreender a relação com a mídia. 
meios anteriormente mencionados. Tal estratégia com distintas "entradas" na temática do consumo de mídia foi determinante para a triangulação dos dados - quando "os pesquisadores assumem diferentes perspectivas sobre uma questão em estudo" (Flick, 2009, p. 63) -, possibilitando explorar de forma bastante aprofundada a relação entre este consumo e o sonho das aspirantes a modelo.

A seguir, apresenta-se um recorte na totalidade de dados construídos sobre o consumo midiático das jovens a fim de traçar um panorama geral da participação da mídia no desejo de ser modelo.

\section{0 consumo midiático e o sonho de ser modelo}

Mais da metade das entrevistadas localizou 0 início do seu desejo de ser modelo na infância, antes dos nove anos. Quando questionadas sobre 0 que as levou a pensar nessa profissão, as respostas giram em torno de cinco razões principais, com o consumo de conteúdos sobre as modelos na mídia tomando a frente ${ }^{9}$. Nas respostas, há citações sobre modelos na TV, no rádio, no cinema, nas revistas e na mídia em geral, sem especificação de meio.

Apesar de não ter relação direta com o consumo midiático operado pelas garotas, a resposta à questão "qual a modelo que mais admira?" ajuda a compreender o quanto a exposição midiática está implicada no apreço e na admiração por determinadas personagens. Ao todo, nove modelos foram citadas, as quatro primeiras são: Gisele Bündchen (mais da metade das jovens a indicou), Ana Hickmann, Naomi Campbell e Isabeli Fontana. As demais, Heidi Klum, Fernanda Lima, Luiza Brunet, Grazi Massafera e Kate Moss, tiveram apenas uma citação cada.

Gisele muito provavelmente seja o caso de maior sucesso no mundo das modelos; Ana Hickmann, após nove anos 'modelando', partiu para uma carreira promissora diante das câmeras de televisão. Naomi Campbell aparece em terceiro e é a modelo negra mais famosa no mundo. Especulase que essa preferência possa estar relacionada ao fato de que algumas das entrevistadas eram negras e também pela presença midiática de Naomi para além das passarelas, mesmo que em meio a escândalos. Isabeli Fontana, além de top model internacional, coleciona ex-namorados famosos ${ }^{10} \mathrm{e}$ estampa páginas nas revistas de fofoca.

As modelos menos citadas também expandiram seus horizontes profissionais e midiáticos: Heidi Klum e Fernanda Lima iniciaram a carreira como modelos e hoje são apresentadoras de TV; Grazi Massafera foi miss, modelo, participante de Big Brother e hoje é atriz; Luiza Brunet é uma das primeiras modelos de grande sucesso no Brasil, 
tendo atuado como atriz e participado de vários programas de TV. Por fim, Kate Moss talvez seja a única a não se dedicar a nenhuma outra atividade sistemática, mas já flertou com o mundo do rock e do cinema em função dos namorados famosos e assinou coleções de roupas para grandes marcas.

Esse quadro geral das modelos mais admiradas leva a inferir que a exposição na mídia para além da carreira de modelo pode ser determinante para a projeção que elas alcançam junto ao grupo pesquisado, seja em relação ao alcance do meio em que estão expostas (TV aberta ou por assinatura, por exemplo) ou ao tempo de exposição (Naomi Campbell e Luiza Brunet podem ser consideradas veteranas).

Quando questionadas sobre onde buscam informações sobre a carreira, a mídia reinou como a principal fonte de informações para as garotas, chegando quase à totalidade das entrevistadas, ainda que algumas tenham indicado mais de um espaço de busca. Importante destacar que essa foi a segunda pergunta do questionário ${ }^{11} \mathrm{e}$ também teve resposta totalmente espontânea, ou seja, o assunto "mídia" ainda não estava em pauta, diferentemente de outras perguntas posteriores relacionadas especificamente ao consumo de meios. 0s demais espaços possuem pouca relevância no quadro geral e incluem os profissionais de agências e amigas que são modelos como fontes.
Quando a questão remetia especificamente ao consumo de conteúdos sobre modelos nos meios de comunicação, a internet foi voluntariamente a mais citada, faltando pouco para que a totalidade das garotas a indicasse. Na sequência, foram citados a TV, as revistas (praticamente um terço das entrevistadas citou cada um desses meios) e 0 rádio, que foi lembrado por apenas uma jovem. Já se adianta que a internet é o meio mais presente no cotidiano das garotas, comparativamente aos demais que foram focalizados no questionário: televisão, rádio, revistas, jornal e cinema. Mais de dois terços acessam diariamente a internet e este é 0 único meio que nenhuma garota respondeu "nunca" acessar.

A internet como um todo, sem especificação de site, é a forma como o meio foi espontaneamente mais citado, o que revela que as garotas consomem conteúdos sobre modelos em vários ambientes digitais. As redes sociais e os blogs aparecem em segundo; as redes citadas foram Orkut, Facebook, Youtube, Instagram, e Pinterest, sendo que as duas últimas exploram basicamente imagens, o que está diretamente associado ao trabalho de uma modelo, pois, como declara Ruggi (2005), ao definir a atividade, este é um ofício de especialistas não $d a$ aparência, mas em aparecer. Os sites de agências de modelos também tiveram citações, e eles são consultados principalmente para saber como é feita a seleção para formar 0 casting (portfólio) de modelos da empresa. 
Quando questionadas suas preferências na internet, sem especificação de assunto, podese dizer que os endereços que tratam de temas como moda e beleza têm proeminência, uma vez que, de um total de 34 sites diferentes citados, 25 têm relação com esse universo (moda, beleza, revistas, agências de modelo). E, mesmo que 0 Facebook, o Google e o Youtube sejam mais citados no geral, as garotas indicaram usar também esses três espaços para efetuar pesquisas sobre 0 mundo das modelos. E, concluindo o resumo sobre a internet, na questão sobre 0 consumo de conteúdos específicos de modelos, obtiveram-se as seguintes respostas, na ordem: imagens de modelos, sites de agências, vida das modelos famosas, entrevistas com profissionais de sucesso, desfiles e concursos, dificuldades na carreira, blogs e páginas de modelos.

A TV aberta e também por assinatura têm menos indicações de consumo do que a internet, tanto no contato diário quanto no que tange aos assuntos sobre modelos. No geral da TV, os reality shows que buscam encontrar a nova top model de sucesso são bastante citados, principalmente no consumo de TV paga. Inferese que estes programas façam sucesso por, supostamente, apresentarem a "realidade" do mercado e apostarem na fórmula do conto de fadas: milhares de inscritas, mas só uma é alçada à categoria de top model. Além disso, possuem um caráter pedagógico, com aulas e dicas sobre como posar para fotos, desfilar ou como se vestir para concorrer a um trabalho. Contudo, acompanhando os episódios, é possível perceber que, entre uma e outra dificuldade da carreira que é abordada, a glamourização das sessões de fotos, as produções de moda e a beleza prevalecem. As demais citações de consumo na TV aberta e por assinatura giram em torno de desfiles, programas de entrevistas que conversam com modelos e concursos de Miss.

Explorando os dados sobre 0 tipo de programação preferida, na TV aberta desponta a novela, espaço em que algumas ex-modelos figuram. Já na TV por assinatura, a preferência é pelos seriados, mas os programas de moda surgem na sequência, e estes, por sua vez, podem ser associados ao universo das modelos, mesmo que direta ou indiretamente. Em quinto lugar, surgem os programas de beleza e, caso se somassem os índices alcançados pelos gêneros moda e beleza (muitas vezes, esses assuntos aparecem associados), estes figurariam em primeiro lugar, ultrapassando os seriados.

No consumo de TV por assinatura, vê-se uma expressiva participação da mídia no sonho de ser modelo, isso porque seis programas que estão entre os cinco mais citados (há alguns empates) podem ser relacionados com a carreira e com o glamour que ela evoca. Na ordem: 0 reality America's next top model, da Sony; os programas Superbonita e Base Aliada, do GNT; What not to wear, do Discovery H\&H; Vamos Combinar e GNT Fashion, também do GNT. Aliás, juntamente com a rede Telecine, 0 canal GNT é 0 mais citado na TV paga. A Globo desponta na TV aberta. 
É preciso considerar que a quantidade de programas e canais que trazem conteúdos sobre modelos na TV paga é bem maior, assim como a segmentação deste meio pode tê-lo feito se destacar. Com isso, não se pretende afirmar que a programação da TV aberta não traga em seus programas conteúdos sobre moda, beleza ou mesmo alguma pauta sobre modelos, o que ocorre é que estes assuntos estão pulverizados em programas não exclusivos desta temática, contrariamente ao que se vê na televisão paga.

0 consumo de revistas não é tão expressivo em sua frequência, contudo, ele é bastante voltado a temas que envolvem a vida e o trabalho das modelos, já que o gênero "moda" alcançou 0 primeiro lugar nas indicações de consumo deste meio. E quando as garotas citaram os títulos de preferência, dos 16 indicados, apenas três não fazem parte dos gêneros "moda", "femininas" e "adolescente", segmentos nos quais as modelos têm considerável espaço. Como conteúdos mais apreciados nas páginas, as fotos das modelos alcançaram 0 primeiro lugar.

Os outros três meios focalizados - rádio, jornal e cinema - apresentaram um consumo de menor regularidade e com menor participação no quadro geral sobre 0 universo das modelos, ainda que tenha havido citações a esse respeito. Em função das dimensões do artigo, estes meios não serão abordados. No entanto, na análise geral dos meios, foi possível visualizar a prática das garotas na construção do seu fluxo de consumo, em que os sete meios investigados participam, de forma relativamente intensa, na busca por informações sobre a carreira.

Até aqui se tratou sobre os dados a partir de um olhar quantitativo, mas para chegar a um entendimento global do consumo midiático, desde a perspectiva de García Canclini (2006), buscaramse nos usos, nos sentidos e nas apropriações ${ }^{12}$ operadas pelas jovens indícios que ajudassem a compreender a integralidade do fenômeno. Sabe-se que incorporar a mirada transdisciplinar reivindicada pelo autor não é tarefa fácil, ainda que seja possível identificar que vários elementos entram em cena nas articulações entre 0 consumo midiático e o desejo de ser modelo, mesmo que com frequência e forças distintas, como se tratará de forma resumida a seguir.

\section{0 consumo como cenário de objetivação de} desejos é a perspectiva mais proeminente nas práticas de consumo midiático das garotas. 0 mapeamento possibilitou perceber o quanto as informações midiatizadas sobre as modelos ajudam a despertar e manter 0 sonho de seguir essa profissão. Um desejo que está para além das necessidades, como argumenta GarcíaCanclini (2006), e que não é satisfeito pelas instituições. Martín-Barbero (1995) destaca que o desejo orienta o nosso consumo e, no caso das 
jovens desta pesquisa, pode estar implicado na predileção por produtos midiáticos que tratem do universo das modelos.

Campbell (2001) contribui para explicar essa relação entre sonho e consumo midiático, já que o prazer derivado da imaginação é colocado como ponto-chave de compreensão do fenômeno. E aqui se pressupõe que o prazer resida no exercício de imaginar-se na situação midiática consumida. E o que os dados construídos em campo demonstraram é que quando as jovens tomam alguma modelo como exemplo de onde gostariam de chegar, direcionam seu desejo a um sujeito em particular que personifica a expectativa, 0 desejo.

García Canclini (2006), no pouco que trata dessa perspectiva de entendimento do fenômeno, enuncia que o consumo como fruto do desejo está para além das necessidades. Ele não cita Lacan, mas esse é justamente um dos pressupostos de sua argumentação, segundo Rosa (2010). A autora assinala a distância entre a organização das necessidades e dos desejos, e explica que o psicanalista introduz os valores de uso, de desejo e de gozo dos objetos como funções distintas. Ou seja, o consumo serve a outras ordens, tem uma outra lógica, ou melhor, uma ausência de lógica, pois ele opera em outra gramática não acionada pelo consciente. Tanto é que essa perspectiva do desejo na proposta de análise sociocultural do consumo de GarcíaCanclini (2006), muitas vezes, é tomada como pertencente a uma lógica irracional.
Contudo, o que se viu nas práticas de consumo de mídia de algumas garotas é que o sonho de ser modelo organiza-as, em parte. Por exemplo, nas buscas de conteúdos sobre modelos na internet, há uma procura consciente de conteúdos específicos, como as histórias das modelos que fazem sucesso hoje. Portanto, se no tratamento dado a essa dimensão do desejo no consumo de bens materiais e simbólicos por García Canclini, ele é irracional e ilógico, no consumo midiático de algumas garotas ele é organizado e objetivo, com vistas a buscar algo muito específico: a aproximação com o universo das modelos e, quiçá, a penetração neste universo a partir do que 0 consumo midiático as prepararia para tanto. Ou apenas estariam buscando insumos para alimentar o sonho, a fantasia e o devaneio, se 0 entendimento de tais indícios empíricos segue 0 aporte de Campbell (2001).

Sobre os aspectos de distinção inscritos no consumo midiático das jovens, a posição de classe pode interferir principalmente no acesso aos meios, conquanto não se tenha um quadro muito claro das diferenças de consumo orientadas por essa dimensão. A classe pode ser determinante para os usos do conteúdo midiático, mobilizados pelas competências culturais, nos termos de Martín-Barbero; no entanto, não foi possível discutir a fundo essa relação em função de algumas decisões metodológicas. Trabalhar com maior número de informantes, aplicando técnicas distintas com cada grupo, fez com que não se pudesse apreender algumas correlações entre 
consumo, classe, preferências, usos e sentidos, já que cada aspecto foi investigado em um grupo distinto. Também há o fato de que a classe não foi 0 recorte a partir do qual se investigou 0 objeto empírico, a dimensão do sonho/projeto de ser modelo foi quem ordenou, em maior medida, a construção do grupo investigado. Ainda assim, cabe destacar que a metade das jovens que participaram da pesquisa foi contatada em quatro seleções de modelo realizadas em Porto Alegre. Nestas seletivas, um expressivo número de jovens era de classes populares.

Dito isso, pelas especificidades do "bem" que se focaliza, entende-se que os aspectos de distinção inscritos nesse consumo talvez estejam mais presentes no capital simbólico, que é 0 conhecimento sobre a carreira e as competências dele advindas, e não tanto nas formas de acesso que poderiam ser mais ostensivas como demarcadores de classe. Dito de outro modo, o tipo de conteúdo consumido, a frequência, a quantidade de informações e as formas de apropriação podem ser mais determinantes para distinguir-se em meio ao grupo de aspirantes.

Quando as jovens buscam referências para se inspirar ou imitar nas fotos de top models consagradas, elas podem objetivar uma distinção daquelas que não possuem esse conhecimento, ou almejam distinguir-se das demais ao se aproximar de quem já tem sucesso. Embora sejam apenas suposições, essas informações podem ser tomadas como um capital que elas incorporam e, assim, considera-se o processo como um operador de distinção dentro da lógica consumidora indicada por García Canclini.

Outra leitura possível dos aspectos de distinção inscritos no consumo midiático das jovens pode se relacionar à noção de corpo como capital de Goldenberg (2007). Para as jovens que querem ser modelo, ter o padrão de aparência de uma profissional é fator de distinção na busca pela carreira. Ou ainda, citando o estudo de Pereira (2008), sobre os ensinamentos do curso de modelos na favela no Rio de Janeiro: quando as alunas aprendem a ter uma nova relação com 0 corpo, mais próxima do uso consciente das classes altas, elas adquirem hábitos não condizentes ao ethos do seu meio social, o que pode servir também como fator de distinção.

Porém, o que está em jogo aqui nesta perspectiva não é propriamente o corpo como capital que as distinguiria, mas o consumo midiático dessas garotas em busca de cuidar, tratar, melhorar e modificar o próprio corpo. 0 interesse pelos cuidados com o físico, seja nas dietas, seja nos exercícios praticados pelas modelos famosas, foi citado no questionário de consumo, a busca pelas medidas da Gisele Bündchen também, mesmo que não tenham sido recorrentes.

0 que esses dados podem indicar é que existe, sim, um reconhecimento dessa distinção capitaneada pelo corpo na profissão, e o midiático ofereceria instruções ou referências de como agir para aprimorar tal capital ou, seguindo a argu- 
mentação de Campbell (2001), apenas ajudaria a fantasiar em torno de um corpo perfeito. Enfim, em relação ao consumo midiático, essa lógica de distinção pode estar no conhecimento que se tem de práticas de cuidados com o corpo e a beleza, ao menos para um grupo menor de garotas.

Ainda assim, em relação ao consumo deste padrão de beleza e às táticas empregadas para se aproximar dele, essa perspectiva de distinção pode ser um tanto redutora se pensada apenas em termos de classe, sem considerar as práticas e a criatividade das garotas para ter acesso a conteúdos sobre a carreira de modelo, ou mesmo a técnicas de embelezamento mais acessíveis.

A ponderação anterior leva à próxima lógica identificada no consumo, a de integração. Esta perspectiva pode ser tomada como o contraponto da anterior: aqui, o consumo é fator integrador de classe, de socialização. Com isso, não se desconsideram os elementos de distinção inscritos no ato de consumir, porém, pressupõese que, para que a distinção se opere, é preciso haver um compartilhamento de sentidos a respeito. Também se leva em conta que a própria carreira opera dentro dessa lógica, uma vez que reúne em torno de uma mesma atividade distintos perfis socioculturais, cujo elemento agregador é a beleza.

0 consumo midiático das jovens pode ser um exemplo de integração, quando se observam os produtos preferidos pela maioria: as telenovelas no consumo de televisão aberta e 0 Facebook no acesso à internet. Outro elemento integrador, agora mais relacionado ao mundo das modelos, é a admiração por Gisele Bündchen, pois a maioria cita seu nome como a top preferida. E, já que a modelo é pauta nos mais diversos meios, é possível perceber que, independentemente do acesso, há um compartilhamento geral dos sentidos de sucesso que ela representa.

\section{A racionalidade sociopolítica interativa também} foi identificada nas práticas de consumo das jovens, ainda que se tenha apenas um exemplo. Nesta dimensão, a ação dos sujeitos no cotidiano entra em foco, com estratégias diferenciadas de aquisição e utilização dos bens midiáticos. Para driblar questões de acesso, uma garota de 16 anos de Porto Alegre, que não dispõe de TV por assinatura na residência, desenvolveu uma tática específica, a qual, nos termos de De Certeau (2007), se constitui da "arte do fraco". Ela depende das visitas à casa da irmã para assisti-la ou então a consulta sobre seus interesses, para, assim, buscar o conteúdo na internet: "como eu não tenho recurso pela televisão, aí eu vou pro Youtube às vezes, ou pergunto pra minha irmã, ‘bah, e aí, já saiu desfile tal?’”.

0 amplo uso da internet pelas jovens entrevistadas pode indicar que ela seja uma aliada em relação a outras táticas operadas dentro do consumo midiático, contudo, estas não foram pontuadas explicitamente pelas jovens. E aqui, também é possível inferir que a lógica de ascensão que a carreira permite pode estar implicada na disputa pelo espaço social que caberia às modelos. 
0 esforço realizado neste artigo foi 0 de identificar as lógicas inscritas no consumo identificadas por García Canclini dentro de um recorte muito específico: 0 consumo midiático sobre beleza feminina e o universo das modelos como um todo. Devido a essa peculiaridade, não foi possível identificar as seis perspectivas com base nas práticas das jovens. Deste modo, os aspectos ritualísticos do consumo e a racionalidade econômica, baseada na reprodução do capital, não foram explorados. 0 que não significa que não estejam implicados nas práticas dessas garotas, porém os instrumentos de pesquisa não possibilitaram sua emersã $0^{12}$.

\section{Considerações Finais}

Neste texto, tentou-se trazer alguns dados que pudessem traçar o panorama da participação da mídia no desejo de ser modelo e compreender as lógicas inscritas no consumo midiático das jovens investigadas, desde 0 aporte de García Canclini (2006). 0 trabalho de campo foi recortado para atender às exigências de um artigo e, portanto, a discussão acerca da perspectiva sociocultural do consumo em alguns momentos remeteu a dados que não foram apresentados em sua totalidade. Contudo, entende-se que os objetivos propostos foram contemplados e pôde-se discutir o quanto a mídia assume um lugar privilegiado no sonho de ser modelo, visto que é tanto legitimadora da profissão como impulsionadora do desejo.
Legitimadora porque todas almejam adentrar 0 espaço midiático a partir da carreira e porque 0 reconhecimento das profissionais atuantes por parte das garotas depende do espaço que ocupam no âmbito midiático. E é impulsionadora, tendo em vista que se constitui como a principal fonte de informações sobre a profissão para o grupo investigado, com grande número de citações espontâneas a esse respeito.

Pode-se concluir que, como propulsora do sonho, a mídia age desde a fase infantil, com mais da metade das garotas indicando uma idade inferior aos nove anos para 0 despertar do desejo, embora 0 índice das que sinalizam a mídia como a principal razão para esse interesse seja menor. Por se tratar de um período de vida em que o lúdico e a fantasia estejam em destaque, poder-se-ia dizer que o processo de sonho que a carreira desperta seria estimulado. Entretanto, o passar dos anos não elimina esse caráter lúdico e fantasioso da relação que as garotas estabelecem com os conteúdos midiáticos do universo da modelagem. Pelo contrário, pareceu se exacerbar em alguns casos.

Para concluir, gostaria-se de lançar alguns apontamentos sobre a participação da mídia na construção desse desejo, mesmo que eles transcendam a discussão sobre 0 consumo e tenham sido suscitados em função de outros procedimentos de pesquisa que não foram abordados no texto. Ao longo dos quatro anos 
de estudo, foram realizadas quatro observações participantes em seleções de modelo de Porto Alegre. Ali, se pode perceber que o padrão de aparência das candidatas é muito destoante em relação ao que o mercado das modelos trabalha. Essa constatação da grande inadequação física das garotas, e não se está falando apenas de alguns quilos a mais ou de centímetros a menos, é uma surpresa da pesquisa, pois se pressupunha que as exigências do padrão midiático de beleza feminina incidiriam de uma forma mais acentuada sobre um grupo de garotas que desejasse seguir essa profissão. No entanto, não foi isso que se encontrou em campo. Algumas jovens reconhecem as exigências de magreza, altura e beleza que a profissão requer, mas, mesmo não estando nem próximas disso, não deixam de sonhar e algumas inclusive de tentar espaço na profissão. 0 que torna válida a argumentação de Campbell (2001), para quem o sujeito moderno é um artista do sonho e, pelo que tudo indica, essas garotas são exemplares avançados nessa arte. 0 autor defende que essa aptidão imaginativa cria fantasias tão convincentes que os indivíduos reagem subjetivamente a elas como se fossem reais. Assim, conclui-se que, aparentemente, a mídia opera mais na transmissão dos ideais de fama, glamour e projeção social do que no regramento da aparência destas jovens, que são a maioria dentro do grupo investigado.

\section{Referências}

APPADURAI, Arjun. La modernidad desbordada.

Dimensiones culturales de la globalización. Montevideo: Ediciones Trilce, 2001.
BAUDRILLARD, Jean. A sociedade de consumo. Lisboa: Edições 70, 1995.

\section{BAUMAN, Zigmunt. Vida para consumo: a}

transformação de pessoas em mercadoria. Rio de Janeiro: Jorge Zahar Ed., 2008.

\section{CAMPBELL, Colin. A ética romântica e o espírito do} consumismo moderno. Rio de Janeiro: Rocco, 2001.

CERTEAU, Michel De. A invenção do cotidiano. Petrópolis: Vozes, 2007.

DEL PRIORE, Mary. Corpo a corpo com a mulher: pequena história das transformações do corpo feminino no Brasil. São Paulo: Editora Senac, 2000.

FLICK, Uwe. Qualidade na pesquisa qualitativa. Porto Alegre: Artmed, 2009.

GARCÍA CANCLINI, Néstor. El Consumo Cultural: una propuesta teórica. In: SUNKEL, Guilhermo. El consumo cultural en América Latina. Construcción teórica y líneas de investigación. $2^{\text {a }}$ Ed. ampliada y revisada. Bogotá: Convenio Andrés Belo, 2006. p. 72-95. Consumidores e cidadãos. Rio de Janeiro: UFRJ, 2005.

GOLDENBERG, Mirian. 0 corpo como capital. In: GOLDENBERG. Mirian (org.). 0 corpo como capital. Barueri: Estação das Letras e Cores Editora, 2007. p. 17-31

JACKS, Nilda. (org). Meios e audiências II: a consolidação dos estudos de recepção no Brasil. Porto Alegre, Sulina, 2014.

JACKS, Nilda et al. Meios e audiências: a emergência dos estudos de recepção no Brasil. Porto Alegre, Sulina, 2008.

LIPOVETSKY, Gilles. A Terceira Mulher: permanência e revolução do feminino. São Paulo: Companhia das Letras, 2000.

MARTIN-BARBER0, Jesús. Dos meios às mediações: comunicação, cultura e hegemonia. Rio de Janeiro:

Editora UFRJ, 2003. 
PEREIRA, Claudia da Silva. Gisele da favela: uma análise antropológica sobre a carreira de modelo. 2008. 218p. Tese (Doutorado em Sociologia e Antropologia) Programa de Pós-Graduação em Sociologia e Antropologia. UFRJ. Rio de Janeiro, 2008.

ROSA, Márcia. Jacques Lacan e a clínica do consumo. In: Psicologia Clínica. Rio de Janeiro. Vol. 22, N. 1, p. 157-171, 2010.

RUGGI, Lenita Oliveira. Aprendendo a ser a

corporificação da beleza: pesquisa com alunas de uma escola de modelos. 2005. 110 f. Dissertação (Mestrado em Sociologia) Programa de Pós-graduação em Sociologia; UFPR. Curitiba, 2005.

SCHMITZ, Daniela. Vivendo um projeto em família: consumo midiático, beleza feminina e o sonho juvenil de ser modelo profissional. Tese (Doutorado em Comunicação e Informação) Programa de Pósgraduação em Comunicação e Informação da UFRGS. Porto Alegre, 2013.

TOALDO, Mariângela; JACKS, Nilda. Consumo midiático: uma especificidade do consumo cultural, uma antessala para os estudos de recepção. XXII Encontro da Compós, 2013, Salvador. Anais... Salvador, 2013.

WOLF, Naomi. 0 mito da beleza: como as imagens de beleza são usadas contra as mulheres. Rio de Janeiro: Rocco, 1992. 


\begin{tabular}{|c|c|}
\hline $\begin{array}{l}\text { Female beauty media consumption } \\
\text { and the dream of becoming } \\
\text { a professional model }\end{array}$ & $\begin{array}{l}\text { Consumo mediático de la } \\
\text { belleza femenina y el sueño } \\
\text { de ser modelo profesional }\end{array}$ \\
\hline $\begin{array}{l}\text { Abstract } \\
\text { This paper discusses how media consumption of } \\
\text { the modeling industry by average young women } \\
\text { might arouse in these girls the desire to follow in } \\
\text { their footsteps. Garcia Canclini's Sociocultural } \\
\text { Consumption perspective and Campbell's ideas about } \\
\text { contemporary hedonism-consumption relationship } \\
\text { serve as its primary reference points. The following } \\
\text { study still presents data gathered among a sample } \\
\text { of } 120 \text { young women. These are the key findings: for } \\
\text { the great majority media is the driving force behind } \\
\text { the dream of becoming a model at a very early age. } \\
\text { Yet, even more so than imposing strict model beauty } \\
\text { standards, media instills in them archetypes of fame, } \\
\text { glam, glitter and social projection harnessed to } \\
\text { professional modeling. } \\
\text { Keywords } \\
\text { Media Consumption. Modeling. Dream. }\end{array}$ & $\begin{array}{l}\text { Resumen } \\
\text { Este texto discute como el consumo mediático del } \\
\text { universo de las modelos profesionales puede estar } \\
\text { relacionado con el deseo de las jóvenes en seguir la } \\
\text { profesión. El teórico referencial parte de la perspectiva } \\
\text { sociocultural del consumo de García Canclini y de } \\
\text { las ideas de Campbell sobre las relaciones entre } \\
\text { el consumo y el hedonismo moderno. Presenta } \\
\text { algunos datos construidos a partir de entrevistas y } \\
\text { cuestionarios aplicados a un grupo de } 120 \text { mujeres } \\
\text { jóvenes. Como principales resultados, se destaca que, } \\
\text { para la mayoría, los medios de comunicación actúan } \\
\text { como propulsora del sueño desde la etapa infantil e } \\
\text { intervienen más en la transmisión de los ideales de la } \\
\text { fama, el glamour y la proyección social de que, en la } \\
\text { instrucción de la apariencia de las jóvenes. } \\
\text { Palabras clave } \\
\text { Consumo mediático. Modelo. Sueño. }\end{array}$ \\
\hline
\end{tabular}




\section{Expediente}

A revista E-Compós é a publicação científica em formato eletrônico da Associação Nacional dos Programas de Pós-Graduação em Comunicação (Compós). Lançada em 2004, tem como principal finalidade difundir a produção acadêmica de pesquisadores da área de Comunicação, inseridos em instituições do Brasil e do exterior.

\section{E-COMPÓS I www.e-compos.org.br I E-ISSN 1808-2599}

Revista da Associação Nacional dos Programas de Pós-Graduação em Comunicação.

Brasília, v.18, n.2, maio/ago. 2015.

A identificação das edições, a partir de 2008, passa a ser volume anual com três números.

Indexada por Latindex I www.latindex.unam.mx

\section{CONSELHO EDITORIAL}

Alexandre Rocha da Silva, Universidade Federal do Rio Grande do Sul, Brasil Alexandre Farbiarz, Universidade Federal Fluminense, Brasil Ana Carolina Damboriarena Escosteguy, Pontifícia Universidade Católica do Rio Grande do Sul, Brasil

Ana Carolina Rocha Pessôa Temer, Universidade Federal de Goiás, Brasil Ana Regina Barros Rego Leal, Universidade Federal do Piauí, Brasil André Luiz Martins Lemos, Universidade Federal da Bahia, Brasil Andrea França, Pontifícia Universidade Católica do Rio de Janeiro, Brasil Antonio Carlos Hohlfeldt, Pontifícia Universidade Católica do Rio Grande do Sul, Brasil

Arthur Ituassu, Pontifícia Universidade Católica do Rio de Janeiro, Brasil Álvaro Larangeira, Universidade Tuiuti do Paraná, Brasil Ângela Freire Prysthon, Universidade Federal de Pernambuco, Brasil César Geraldo Guimarães, Universidade Federal de Minas Gerais, Brasil Cláudio Novaes Pinto Coelho, Faculdade Cásper Líbero, Brasil Daisi Irmgard Vogel, Universidade Federal de Santa Catarina, Brasil Daniela Zanetti, Universidade Federal do Espírito Santo, Brasil Denize Correa Araujo, Universidade Tuiuti do Paraná, Brasil Eduardo Antonio de Jesus, Pontifícia Universidade Católica de Minas Gerais, Brasil

Eduardo Vicente, Universidade de São Paulo, Brasil

Elizabeth Moraes Gonçalves, Universidade Metodista de São Paulo, Brasil Erick Felinto de Oliveira, Universidade do Estado do Rio de Janeiro, Brasil Francisco Elinaldo Teixeira, Universidade Estadual de Campinas, Brasil Francisco Paulo Jamil Almeida Marques, Universidade Federal do Ceará, Brasil Gabriela Reinaldo, Universidade Federal do Ceará, Brasil Gisela Grangeiro da Silva Castro, Escola Superior de Propaganda e Marketing, Brasil

Goiamérico Felício Carneiro Santos, Universidade Federal de Goiás, Brasil Gustavo Daudt Fischer, Unisinos, Brasil

Herom Vargas, Universidade Municipal de São Caetano do Sul, Brasil
Itania Maria Mota Gomes, Universidade Federal da Bahia, Brasil Janice Caiafa, Universidade Federal do Rio de Janeiro, Brasil Jiani Adriana Bonin, Universidade do Vale do Rio dos Sinos, Brasil José Afonso da Silva Junior, Universidade Federal de Pernambuco, Brasil José Luiz Aidar Prado, Pontifícia Universidade Católica de São Paulo, Brasil Kati Caetano, Universidade Tuiuti do Paraná, Brasil

Lilian Cristina Monteiro França, Universidade Federal de Sergipe, Brasil

Liziane Soares Guazina, Universidade de Brasília, Brasil Luíza Mônica Assis da Silva, Universidade de Caxias do Sul, Brasil Luciana Miranda Costa, Universidade Federal do Pará, Brasil Malena Segura Contrera, Universidade Paulista, Brasil Marcel Vieira Barreto Silva, Universidade Federal da Paraíba, Brasil Maria Ogécia Drigo, Universidade de Sorocaba, Brasil Maria Ataide Malcher, Universidade Federal do Pará, Brasil Maria Clotilde Perez Rodrigues, Universidade de São Paulo, Brasil Maria das Graças Pinto Coelho, Universidade Federal do Rio Grande do Norte, Brasil

Mauricio Ribeiro da Silva, Universidade Paulista, Brasil

Mauro de Souza Ventura, Universidade Estadual Paulista, Brasil

Márcio Souza Gonçalves, Universidade do Estado do Rio de Janeiro, Brasil Micael Maiolino Herschmann, Universidade Federal do Rio de Janeiro, Brasil Mirna Feitoza Pereira, Universidade Federal do Amazonas, Brasil Nísia Martins Rosario, Universidade Federal do Rio Grande do Sul, Brasil Potiguara Mendes Silveira Jr, Universidade Federal de Juiz de Fora, Brasil Regiane Ribeiro, Universidade Federal do Paraná, Brasil Rogério Ferraraz, Universidade Anhembi Morumbi, Brasil Rose Melo Rocha, Escola Superior de Propaganda e Marketing, Brasil Rozinaldo Antonio Miani, Universidade Estadual de Londrina, Brasil Sérgio Luiz Gadini, Universidade Estadual de Ponta Grossa, Brasil Simone Maria Andrade Pereira de Sá, Universidade Federal Fluminense, Brasil Veneza Mayora Ronsini, Universidade Federal de Santa Maria, Brasil Walmir Albuquerque Barbosa, Universidade Federal do Amazonas, Brasil

\section{COMISSÃO EDITORIAL}

\section{Cristiane Freitas Gutfreind}

Pontifícia Universidade Católica do Rio Grande do Sul, Brasil

\section{Irene Machado}

Universidade de São Paulo, Brasil

Jorge Cardoso Filho

Universidade Federal do Reconcavo da Bahia, Brasil

Universidade Federal da Bahia, Brasil

\section{EQUIPE TÉCNICA}

ASSISTENTE EDITORIAL I Márcio Zanetti Negrini

REVISÃO DE TEXTOS I Press Revisão

EDITORAÇÃO ELETRÔNICA I Roka Estúdio

CONTATO I revistaecompos@gmail.com
COMPóS I www.compos.org.br

Associação Nacional dos Programas de Pós-Graduação em Comunicação

Presidente

Edson Fernando Dalmonte

Programa de Pós-Graduação em Comunicação

e Cultura Contemporânea - UFBA

edsondalmonte@uol.com.br

Vice-presidente

Cristiane Freitas Gutfreind

Programa de Pós-Graduação em Comunicação Social - PUC-RS cristianefreitas@pucrs.br

Secretário-Geral

Rogério Ferraraz

Programa de Pós-Graduação em Comunicação

Universidade Anhembi Morumbi

rogerioferraraz@anhembimorumbi.edu.br 